\title{
EFFECTS OF CONCENTRIC- ECCENTRIC MOTION EXERCISE OF QUADRICEP MUSCLE ON PAIN REDUCTION AND FUNCTIONAL IMPROVEMENT AMONG PATIENTS WITH KNEE OSTEOARTHRITIS
}

\author{
Heru Purbo Kuntono, Budi Utomo, Afif Ghufroni \\ Physiotherapy, School of Health Polytechnics, Surakarta, Indonesia
}

\begin{abstract}
Background: Worldwide, osteoarthritis (OA) is the most common form of arthritis, affecting millions of people. OA can damage any joint. The disorder most commonly affects joints in hands, knees, hips, and spine. Eccentric contraction is a lengthening movement of muscles. During muscle movement, the muscle fiber is stretched under tension from a force greater than the muscle generates. This study aimed to examine the effects of concentric-eccentric motion exercise of quadricep muscle on pain reduction and functional improvement among patients with knee OA.
\end{abstract}

Subjects and Method: This was a randomized control trial conducted at Fitasoma Independent Physiotherapy Practice, from April to August 2017. A total of 24 OA patients was selected for this study, and randomly assigned into two groups: 12 patients with concentric-eccentric motion exercise in the intervention group and 12 patients without the exercise in the control group. The independent variable (the intervention) was concentric-eccentric motion exercise. The dependent variables were pain and functional ability. The pain was measured by a Visual Analog Scale (VAS). The functional ability was measured by the Western Ontario and McMaster Universities Arthritis Index (WOMAC). After intervention, mean scores of pain and functional ability between the two groups were compared and tested by Mann-Whitney test.

Results: Before intervention, the mean scores of pain and functional ability between the two groups were comparable, and it was statistically non-significant, indicating the intended effect of randomization. After intervention, mean score of pain in the intervention group was lower than the control group, and it was statistically significant. After intervention, mean score of functional ability in the intervention group was higher than the control group, and it was statistically significant.

Conclusion: The concentric-eccentric motion exercise of quadricep muscle is effective in reducing pain and improving functional ability of patients with knee OA.

Keywords: concentric-eccentric motion exercise, quadricep muscle, pain, improving functional ability, knee osteoarthritis

\section{Correspondence:}

Heru Purbo Kuntono. Physiotherapy, School of Health Polytechnics, Surakarta, Central Java, Indonesia. Email: herupurbo@gmail.com. Mobile: +628121576205. 